\title{
ИННОВАЦИОННЫЕ РЕШЕНИЯ И ПЕРСПЕКТИВНЫЕ ТЕХНОЛОГИИ В ВЕДУЩИХ ОТРАСЛЯХ НАРОДНОГО ХОЗЯЙСТВА
}

\author{
(c) 2021 Ратнер Дмитрий \\ аспирант \\ Самарский государственный экономический университет, Россия, Самара \\ E-mail: ratner_9d@mail.ru
}

В статье рассматривается отрасль сельского хозяйства в эпоху инновационных внедрений и цифровых решений. Описано, что компаниям, производящим сельскохозяйственные ресурсы, необходимо помочь удовлетворить растущий спрос на продукты питания и оставаться конкурентоспособными с новыми цифровыми предприятиями, которые выходят на рынок. Дан метод использования дифференцированного внесения удобрений, который означает использование удобрений в разных участках поля согласно заранее разработанной карты данного поля, которая основывается на разных видах информации. Предметом исследования является отрасль сельского хозяйства. Объектом исследования выступали инновационные решения и технологии в сфере народного хозяйства. Были рассмотрены работы ведущих специалистов в области народного хозяйства: Ю.А.Савинов, В.П. Якушев, С. Николаенко.

Описана концепция согласованного (точного) земледелия, которая предполагает использование максимально полного набора информации для разработки агротехнических решений, оптимизации их под почвенно-климатические и другие условия, а также дифференцированное применение их для основных технологических операций. Также дан принцип внедрения беспилотных летательных аппаратов для создания карты растительности и ортофотопланов (цифровое изображение местности).

В статье показано, что преимущества цифровых технологий многочисленны и включают повышение рентабельности, улучшение условий содержания животных, улучшение условий труда, лучший мониторинг производства (например, удаленный мониторинг, доступ к данным в реальном времени) и улучшенное предоставление важных производственных данных. Описан процесс формирования карты вегетационного индекса, где отображены зоны с низким и высоким индексом, что становится основой для пятилетнего обобщенного изображения карт.

Дано понятие традиционного животноводства как сектора, которому многие не уделяют должного внимания и который недостаточно обслуживается, хотя он обеспечивает необходимые возобновляемые природные ресурсы. Описанная технология блокчейн может отслеживать происхождение продуктов питания и, таким образом, помогает создавать надежные цепочки поставок продуктов питания и укреплять доверие между производителями и потребителями. Как надежный способ хранения данных, он упрощает использование технологий, управляемых данными, чтобы сделать сельское хозяйство более разумным.

Ключевые слова: инновации, дифференцированное внесение удобрений, беспилотные летательные аппараты, оптимизация, блокчейн, сельское хозяйство, машинное обучение, точное земледелие.

В современном сельском хозяйстве инновации являются важной частью и играют большую роль в аграрной деятельности. В текущем году наблюдаются повышение стоимости поставок, минимизация занятости рабочей силы в отрасли в связи с цифровизацией, а также изменение спроса в отношении прозрачности и устойчивости. Отрасль народного хозяйства понимает важность устранения проблем и старается найти современные решения. За последние 10 лет в сельскохозяйственных технологиях наблюдался огромный рост инвестиций: за последние 5 лет было инвестировано 6,7 млрд. долларов, в прошлом году сумма составила 1,9 млрд. долларов [6].

Компаниям, производящим сельскохозяйственные ресурсы, необходимо помочь удовлетворить растущий спрос на продукты питания и оставаться конкурентоспособными с новыми цифровыми предприятиями, которые выходят 
на рынок. Это ключевая задача, поскольку им нужно изменить свои традиционные инновационные модели и быстро вернуть свои усилия по разработке продуктов, выращиванию, системе удобрений в нужное русло.

Современные методы предполагают использование дифференцированного внесения удобрений. Это означает использование удобрений в разных участках поля согласно заранее разработанной карты данного поля, которая основывается на разных видах информации. Исследователь берет следующие данные для анализа: анализ почвы, карта урожайности, карта рельефа, карта проводимости почвы, потенциальные участки и другие.

Данный метод лежит в основе концепции согласованного (точного) земледелия, которая предполагает использование максимально полного набора информации для разработки агротехнических решений, оптимизации их под почвенно-климатические и другие условия, а также дифференцированное применение их для основных технологических операций [10]. Важно применять строго определенные и обоснованные агротехнические приемы выращивания конкретных культур.

Принцип применения данного метода основывается на внедрении беспилотных летательных аппаратов для создания карты растительности и ортофотопланов (цифровое изображение местности) [4]. Фермер на протяжении трех месяцев проводит аэрофотосъемку в видимом инфракрасном диапазоне, что позволяет увидеть текущее состояние посевов и провести пространственное разделение поля на технологические зоны.

В итоге формируется карта вегетационного индекса, где отображены зоны с низким и высоким индексом, что становится основой для пятилетнего обобщенного изображения карт. Далее карты принимают цифровой формат векторных карт «Shapefile», который формирует набор полигонов с благоприятными участками почв для посева. Затем файлы загружаются непосредственно в универсальный терминал «Amatron 3» [3]. Так, решается проблема сложностей картографирования, мониторинга посевов, оценки всхожести и прогнозов урожайности, а также оптимизации применения цифровых решений на основе традиционных методов ведения народного хозяйства.

Животноводство является одной из ключе- вых отраслей современного сельского хозяйства и важным направлением внедрения инновационных решений и технологий. Традиционное животноводство - это сектор, которому многие не уделяют должного внимания и который недостаточно обслуживается, хотя он обеспечивает необходимые возобновляемые природные ресурсы [7]. Из-за роста населения темпы животноводства были обескураживающими, поэтому были предприняты усилия по внедрению технологий производства продуктов животноводства, направленных на повышение производственного потенциала для благосостояния людей.

Преимущества цифровых технологий многочисленны и включают повышение рентабельности, улучшение условий содержания животных, улучшение условий труда, лучший мониторинг производства (например, удаленный мониторинг, доступ к данным в реальном времени) и улучшенное предоставление важных производственных данных.

Принцип применения состоит в том, что фермеры, занимающиеся молочным скотоводством, чаще всего стали использовать простые цифровые технологии, связанные с процессом доения. Например, цифровой счетчик молока был наиболее часто используемой технологией. Порядка 45\% от общего числа фермеров, отмечают его удобство. Аналогичным образом применяют ошейник - транспондер, датчик потока молока и потребление концентрированного корма, которые стали ключевыми решениями среди 20\% фермеров, выращивающих молочный скот.

Цифровые счетчики молока также были наиболее часто используемыми датчиками для молочных коз, хотя процент был значительно ниже - 9\%. Для коров-сосунов чаще всего использовались фотоаппараты, электронные ушные бирки и электронные системы взвешивания с частотой от $5 \%$ до $7 \%$.

Фермеры, выращивающие мясной скот, больше всего использовали ошейникитранспондеры (14\%), за ними следуют электронные системы взвешивания (9\%). 6\% фермеров сектора молочного скотоводства отдают предпочтение доильному роботу, а также роботууборщику навоза. Робот для автоматической подачи кормов применяют 2\% фермеров, занимающихся молочным и мясным скотоводством. Но практика показывает, что автоматизированный пододвигатель кормов, на который возлага- 
ли надежды, не используется на фермах [1].

Внедрение цифровых технологий в животноводстве сильно различается между различными сельскохозяйственными предприятиями и наиболее распространено на крупных специализированных животноводческих фермах. В целом, простые в использовании датчики и измерительные устройства, например, встроенные в доильный зал, получили большее распространение, чем технологии обработки данных.

Система животноводства также определяет использование цифровых технологий, в результате чего фермеры с навесом с меньшей вероятностью будут использовать цифровые технологии, чем фермеры с системами беспривязного содержания [5]. Изучение личных факторов, определяющих принятие фермерами и перспектив внедрения, может помочь выявить дополнительные препятствия на пути внедрения цифровых технологий и перспективных решений.

Более того, технологические разработки предоставляют фермерам более эффективные, прибыльные и быстрые решения, позволяющие вовремя выполнять процесс, используя возможности управления. Непрерывный мониторинг болезней и их тщательное управление также важны для благополучия животноводческих хозяйств, что нередко отправляют на последний план при внедрении цифровых решений.

Технология блокчейн может отслеживать происхождение продуктов питания и, таким образом, помогает создавать надежные цепочки поставок продуктов питания и укреплять доверие между производителями и потребителями. Как надежный способ хранения данных, он упрощает использование технологий, управляемых данными, чтобы сделать сельское хозяйство более разумным.

Кроме того, при совместном использовании со смарт-контрактами, он позволяет своевременно производить платежи между заинтересованными сторонами, которые могут быть вызваны изменениями данных, появляющимися в цепочке блоков [9]. Актуальны проблемы регистрации транзакций, совершаемых мелкими фермерами, и создания экосистемы для использования технологии блокчейн в продовольственном и сельскохозяйственном секторе.

Одним из примеров корпораций, практикующих технологию, является «DSTE Capital Limited». Благодаря своей цепочке DSTE он улуч- шит состояние в трех основных областях сельскохозяйственной отрасли, а именно в цепочке поставок продуктов питания, безопасности пищевых продуктов и финансовых услугах. Применение технологий «DSTE CHAIN» и «DLT» в сельскохозяйственных цепочках поставок обеспечит цифровую базу данных, в которой регистрируются, отслеживаются, отслеживаются и осуществляются операции с физическими и цифровыми активами [2].

Технология блокчейн обеспечивает прозрачность для всех вовлеченных сторон и облегчает сбор надежных данных. Блокчейн может записывать каждый шаг в цепочке создания стоимости продукта [8]. Надежные данные о процессе земледелия очень ценны для разработки средств управления данными и страховых решений, которые сделают сельское хозяйство менее уязвимым.

Таким образом, умное сельское хозяйство характеризуется использованием ИКТ, Интернета вещей (IоT) и различных современных технологий сбора и анализа данных, включая беспилотные летательные аппараты (БПЛА), датчики и машинное обучение. Так, технология блокчейн служит для хранения данных и информации, которые различные участники и заинтересованные стороны генерируют на протяжении всего процесса создания добавленной стоимости, от семян до продажи, при производстве сельскохозяйственной продукции. Это гарантирует, что данные и информация прозрачны для вовлеченных субъектов и заинтересованных сторон, а все записанные данные неизменны.

Многие модели умного земледелия предлагаются и реализуются на основе совместного применения технологий IоT и блокчейн. Фермы предлагают «легкую архитектуру на основе блокчейнов для умных тепличных хозяйств». В теплицах датчики действуют как частный локальный блокчейн, которым централизованно управляет владелец. С точки зрения производителей, использование технологии блокчейн помогает установить доверительные отношения с потребителями и укрепить репутацию их продуктов за счет прозрачного предоставления информации об отдельных продуктах в блокчейне.

Предприятия могут лучше достичь ценности своей продукции и, таким образом, повысить свою конкурентоспособность. Это затруднит удержание поставщиков мошеннических и некачественных товаров на рынках и заставит всех 
поставщиков повышать качество продукции во всем сельскохозяйственном и пищевом сектоpax. С точки зрения потребителей, блокчейн делает доступной правдивую и надежную информацию о том, как производится еда и как с ней совершаются транзакции.

Современные методы внедрения цифровых и передовых решений также предполагают использование дифференцированного внесения удобрений. Данный метод лежит в основе концепции согласованного (точного) земледелия, с помощью которого решается проблема сложностей картографирования, мониторинга посевов, оценки всхожести и прогнозов урожайности, а также оптимизации применения цифровых решений на основе традиционных методов ведения народного хозяйства.

\section{Библиографический список}

1. Animal Husbandry [Электронный pecypc].URL: https:/www.toppr.com/guides/biology/strategies-forenhancement-in-food-production/animal-husbandry/ (дата обращения: 28.09.2021).

2. Ноо J. Benefits of Blockchain Technology in Agriculture Industry [Электронный ресурс].URL: https://agfuse.com/ article/benefits-of-blockchain-technology-in-agriculture-industry (дата обращения: 28.09.2021).

3. Как эффективно делать подкормку азотными удобрениями [Электронный ресурс].URL: https://agroportal. ua/publishing/lichnyi-vzglyad/kak-effektivno-delat-podkormku-azotnymi-udobreniyami/ (дата обращения: 28.09.2021).

4. Кошкин Ф. Точное земледелие: проблемы и перспективы / Ф.Кошкин // Защита растений: инновации в АПК. - 2020.- № 10 (299). - С. 2-4.

5. Марусич А. Г. Скотоводство. Воспроизводство стада: учебно-методическое пособие / А. Г. Марусич. - Горки: БГСХА, 2017. - С. 64.

6. Николаенко C. 10 сфер, в которых можно действительно заработать миллиарды [Электронный ресурс].URL: https://brodude.ru/10-sfer-v-kotoryh-mozhno-dejstvitelno-zarabotat-milliardy/ (дата обращения: 28.09.2021).

7. Новицкий И. Современное животноводство: состояние и основная продукция отрасли [Электронный реcypc].URL: https://сельхозпортал.pф/articles/sovremennoe-zhivotnovodstvo/ (дата обращения: 28.09.2021).

8. Савинов Ю.А. Использование технологии «Блокчейн» в международной торговле / Ю. А. Савинов, А. Н. Зеленюк, Е. В. Тарановская // Российский внешнеэкономический вестник. - 2020. - № 8. - С. $63-86$.

9. Сураева М.О. Оптимизация материальных ресурсов организации с соблюдением требований экономической безопасности / М. О. Сураева, Т.А. Кулькова // АКТУАЛЬНЫЕ ВОПРОСЫ НАЛОГООБЛОЖЕНИЯ, НАЛОГОВОГО АДМИНИСТРИРОВАНИЯ И ЭКОНОМИЧЕСКОЙ БЕЗОПАСНОСТИ сборнИк НаучныХ статеЙ IV Всероссийской научно-практической конференции. Курск. - 2020. - С. 145-148.

10. Якушев В.П. Интеллектуальные системы поддержки технологических решений в точном земледелии / В.П.Якушев, В.В.Якушев, Д.А.Матвеенко // Земледелие, компьютерные и информационные науки. 2020. — № 1. - 33-38. 